\title{
SISTEMA DE CONTROL BASADO EN ARDUINO PARA UNA CALDERA DE BIOMASA
}

\author{
Martín Balboa, Serafín Alonso, Juan José Fuertes, Antonio Morán, Miguel Ángel Prada \\ Grupo de Investigación en Supervisión, Control y Automatización de Procesos Industriales (SUPPRESS) \\ Dpto. de Ingeniería Eléctrica y de Sistemas y Automática. Área de Sistemas y Automática. \\ Escuela de Ingenierías, Universidad de León, Campus de Vegazana s/n, 24007 León, Spain \\ mbalbf00@estudiantes.unileon.es, saloc@unileon.es, jjfuem@unileon.es, \\ a.moran@unileon.es, ma.prada@unileon.es
}

\section{Resumen}

La biomasa es una energía renovable, cuyo uso se ha visto incrementado en aplicaciones de calefacción y agua caliente sanitaria (ACS). Las calderas de biomasa requieren una limpieza de cenizas y un proceso de combustión óptimo para lograr un funcionamiento eficiente. En este trabajo, se presenta el diseño e implementación de un nuevo quemador y su sistema de control para una caldera de biomasa comercial de $25 \mathrm{~kW}$. Los principales objetivos del sistema de control son reducir las emisiones, aumentar el rendimiento, mejorar el sistema de limpieza y crear un panel supervisión y control con una interfaz gráfica más intuitiva para el usuario. El sistema de control desarrollado esta basado en la plataforma abierta y de bajo coste Arduino, de forma que el usuario puede incorporar futuras mejoras o actualizaciones en el modo de funcionamiento. Con el sistema de control desarrollado, se han conseguido importantes mejoras en cuanto a las emisiones y el rendimiento de la caldera.

Palabras clave: Control, Arduino, Caldera, Biomasa, Emisiones, Eficiencia.

\section{INTRODUCCIÓN}

La biomasa es un combustible de origen renovable, que se considera prácticamente neutro en cuanto a emisiones de $\mathrm{CO}_{2}$ y actualmente se ha constituido en una alternativa a los combustibles fósiles, no solo por su importancia en la reducción de gases de efecto invernadero, sino también debido a su aplicación en distintos sectores como la generación de calor para hogares, comercios, industria y generación de energía eléctrica [12]. Los combustibles sólidos de biomasa son muy utilizados en la generación de calor [10]. En Europa el consumo de pellet está aumentando debido a su uso en aplicaciones como la calefacción y el agua caliente sanitaria (ACS). Aunque a nivel mundial hay un mayor consumo de los combustibles tradicionales como la leña, la falta de tecnología en los países menos desarrollados genera mayores emisiones y peores rendimientos provocando la deforestación y perjuicios para el medioambiente [11].

Dentro de la producción de energías renovables la biomasa tiene bastante importancia a nivel mundial, ya que representa un $70 \%$ de la producción de la energía primaria total frente a otras energías renovables. La biomasa para la producción de electricidad solo supone un $9 \%$ del total de energías renovables, pero en la producción de calor para sectores como la agricultura, el comercial o el residencial, es la fuente principal, con un $96 \%$ frente al resto de energías como la geotérmica y la solar [12].

En 2016, la biomasa sólida representó en todo el mundo un $87 \%$ frente a otras fuentes de biomasa como son el biogás, los biocombustibles líquidos o los residuos industriales y urbanos [14]. Concretamente, para la generación de calor, el tipo de biomasa más utilizado es la biomasa sólida frente a otros tipos de biomasa. Merece la pena destacar el crecimiento que ha tenido en Europa el uso de biomasa para las aplicaciones de calefacción y ACS, mayoritariamente abastecidas con pellets. En este sentido, la instalación de calderas de biomasa en Europa ha tenido un auge desde el año 2004 [10].

Actualmente existen en el mercado empresas que han desarrollado calderas de biomasa de pellet o calderas de gasificación de leña con una tecnología capaz de alcanzar rendimientos mayores, además de controlar y reducir las emisiones. Sin embargo, las calderas de biomasa requieren una limpieza periódica debido a las cenizas y suciedad que se deposita en su interior. Además, tras un uso prolongado, se deben de cambiar ciertos componentes mecánicos y eléctricos. Cuando una caldera tiene cierta antigüedad es difícil encontrar repuestos y aunque el cuerpo de la caldera tiene una vida útil mayor que el quemador, en el mayor de los casos 
no puede sustituirse este último ni realizar cambios en el hardware de la caldera, ya que el software no está públicamente disponible.

En este artículo, se analizan y se presentan mejoras de las deficiencias de una caldera comercial de $25 \mathrm{~kW}$, con el fin de lograr reducir las emisiones, aumentar su rendimiento, mejorar el sistema de limpieza. Para ello, se propone utilizar una plataforma abierta y de bajo coste como es Arduino, que permita realizar actualizaciones de software y por consiguiente, modificaciones también en el hardware [1]. Además, se propone crear una interfaz gráfica más intuitiva para supervisión y control de la caldera por parte del usuario.

Este artículo está estructurado en las siguientes secciones: en la sección 2 se presentan los antecedentes, en la sección 3 se describe el sistema de control diseñado e implementado, los resultados obtenidos se indican en la sección 4 mientras que en la sección 5 se resumen las conclusiones.

\section{CALDERAS DE BIOMASA}

Se pueden distinguir dos tipos de calderas de biomasa, en relación a su tiro: de tiro natural y de tiro artificial [8]. En las calderas de tiro natural, el aumento de presión se produce por la diferencia de densidades entre el aire ambiente y los productos de combustión. En las calderas de tiro artificial, la diferencia de presión se produce por medios mecánicos. El tiro artificial posee las siguientes ventajas frente al tiro natural: facilidad para el control de combustión, incremento de la eficiencia, etc.

En el ámbito de las calderas de tiro artificial [8], se denominan calderas de tiro forzado a aquellas en las que los humos se extraen por la chimenea, impulsándolos con ventiladores desde la parte baja de ésta. Dichos ventiladores trabajan con una presión positiva. Por el contrario, se denominan calderas de tiro inducido a aquellas que crean un vacío parcial en la cámara de combustión mediante extractores situados en la parte alta de la caldera, con el fin de extraer los productos de combustión y hacerlos pasar por la chimenea. En esta situación, los extractores trabajan con presión negativa, también denominada depresión.

El tiro inducido tiene la virtud de evitar las posibles explosiones que se generan cuando las igniciones en los quemadores encienden algunos de los gases presentes en la caldera en las cercanías del quemador [6]. Además, el tiro inducido tiene la ventaja de distribuir uniformemente el oxígeno al quemador, lo que permite quemados más eficientes.

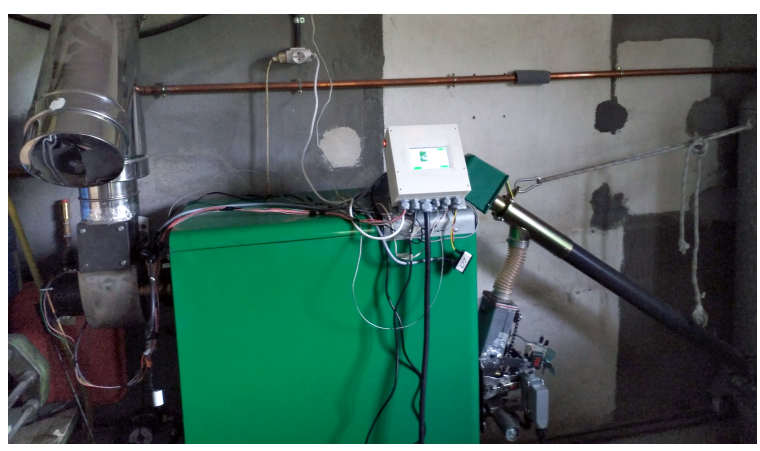

Figura 1: Caldera modelo EcoTec Mini Q

En función del tipo de combustible se pueden distinguir los siguientes tipos de calderas: calderas de leña, pellets, astillas, etc. Los sistemas de combustión de pellets, son sistemas automáticos que controlan la carga de combustible mediante el tiempo de alimentación de un tornillo sinfín que introduce los pellets en el quemador. El flujo másico de combustible puede ser constante o variar para cumplir con las consignas de control y su valor se ajusta mediante el tiempo de apagado/encendido del motor que acciona el sinfín y deposita el combustible en la entrada del quemador cuando éste lo demande [13]. El aire necesario para la combustión se suministra mediante un ventilador o un extractor de humos. La caldera de pellet cuenta con dos entradas de aire, una para el aire primario situada en la rejilla y otra en la parte superior del quemador, en contacto con los gases de la combustión. La ignición de los pellets es automática, mediante una resistencia situada en el quemador y mediante un sensor se detecta la llama. En este tipo de calderas es muy importante mantener la caldera limpia para el buen funcionamiento y durabilidad. En el mercado existen calderas con limpieza de cenizas automática de los intercambiadores, cenicero y quemador.

En una caldera de pellet se distinguen varias partes: el cuerpo de la caldera formado por láminas y tubos de acero; el quemador que tiene la función de realizar la combustión de los pellets; la cámara de combustión que es el lugar donde se quema el combustible; el circuito de humos que son los elementos que conducen los gases al intercambiador; el intercambiador, elemento que transfiere el calor de los gases de la combustión al agua; el circuito de agua que es la zona de la caldera por la que circula el agua para absorber el calor y conducirlo a los emisores de calor; el sistema de limpieza encargado de remover, a través de elementos mecánicos, la ceniza depositada en partes importantes como el quemador y el intercambiador; el alimentador, constituido por un husillo accionado por un motor que introduce los pellets del depósito a la cámara de combustión; 
el depósito de combustible; un sistema de protección para evitar el retorno del fuego; el aislamiento térmico y el revestimiento; un panel de control encargado de procesar los datos de los sensores, interactuar con el operador y controlar los distintos actuadores de la caldera. En la fase experimental de este artículo se ha trabajado con una caldera de pellets de $25 \mathrm{~kW}$ modelo EcoTec Mini Q. En la Fig.1 se puede ver una fotografía de esta caldera.

\section{SISTEMA DE CONTROL DE LA CALDERA}

En este apartado, se presentan los elementos hardware utilizados y se explican los algoritmos software implementados en el sistema de control.

\subsection{MODIFICACIONES DE LA CALDERA}

En las calderas de biomasa de uso doméstico, que disponen de los quemadores de tipo floración de tiro forzado, es habitual encontrarse los siguientes problemas:

- Dado que el alimentador siempre debe estar lleno para que la capa más externa se queme, existe un mayor riesgo de retroceso.

- Es frecuente que la ceniza se acumule en el codo de $90^{\circ}$ del quemador, y como esta zona no es limpiada automáticamente, se suelen crear creosotas que producen la obstrucción en el tubo de alimentación.

- Cuando la temperatura exterior es fría o el aire exterior es húmedo a este tipo de caldera le cuesta arrancar y genera turbulencias.

- El ventilador no regula la velocidad en función del oxígeno presente en la combustión, ya que el sistema de control no dispone de un medidor de oxígeno. Por este motivo, la combustión es incompleta, aumentando el hollín en las paredes de la caldera y disminuyendo la eficiencia debido a esta acumulación y a la inadecuada mezcla de oxígeno-combustible. Además, el flujo de aire máximo que suministra el ventilador, frecuentemente no cumple con la demanda de oxígeno necesaria para una mezcla óptima.

Con el propósito de solventar los problemas del quemador comentados, se ha diseñado un quemador completamente nuevo (véase la Fig. 2), para una caldera modelo EcoTec Mini Q. Este nuevo quemador incorpora un sistema de limpieza que elimina las cenizas moviendo la parrilla de la

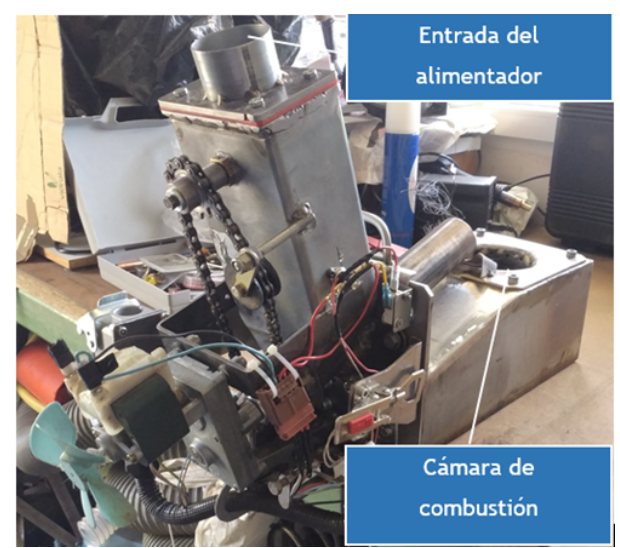

Figura 2: Nuevo quemador de la caldera

cámara de combustión y una válvula rotatoria antirretorno de fuego, detección de fuego y encendido automático.

Para cumplir con los requisitos del nuevo quemador, se diseñó e implementó un sistema de control basado en la plataforma abierta y de bajo coste Arduino.

\subsection{ELEMENTOS UTILIZADOS EN EL SISTEMA DE CONTROL}

En la Fig. 3, se muestra un esquema general del control desarrollado, indicando las conexiones de todos los elementos utilizados: sensores, actuadores, controladores y pantalla táctil.

El controlador principal se implementó sobre un Arduino DUE, mientras que un Arduino UNO realiza las tareas auxiliares para medida y regulación de la velocidad del ventilador.

El controlador principal recibe datos de todos los sensores. La temperatura del agua caliente es medida por dos sensores de temperatura tipo NTC para inmersión, uno para la temperatura de ida y otro para la de retorno. En la salida de humos de la caldera se ubica un sensor termopar para medir la temperatura de gases cuyos datos son recogidos por el Transmisor MAX31855 y enviados por comunicación digital SPI. El oxígeno se mide con un sensor lambda modelo Bosch Lsu 4.9, que requiere del controlador local Lsu 4.9 de LDPerformance. En un conducto del quemador comunicado con la cámara de combustión se encuentra un sensor LDR para detectar la presencia de llama. El Arduino DUE también recibe datos de sensores como el termostato de ambiente, un termostato para detectar un posible retroceso de llama, los finales de carrera que indican la posición del mecanismo de limpieza del quemador, un final de carrera que indica si el quemador ha sido instalado correctamente y dos sensores de nivel ópticos situados 


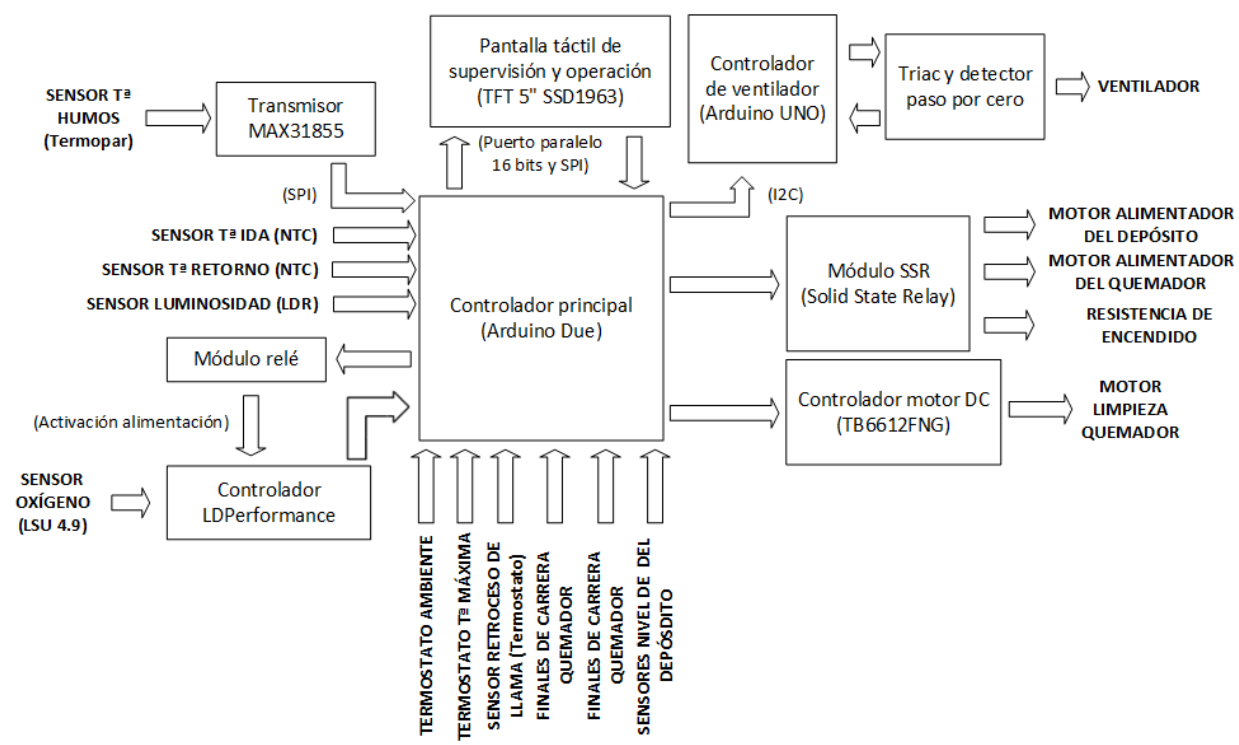

Figura 3: Esquema del sistema de control desarrollado

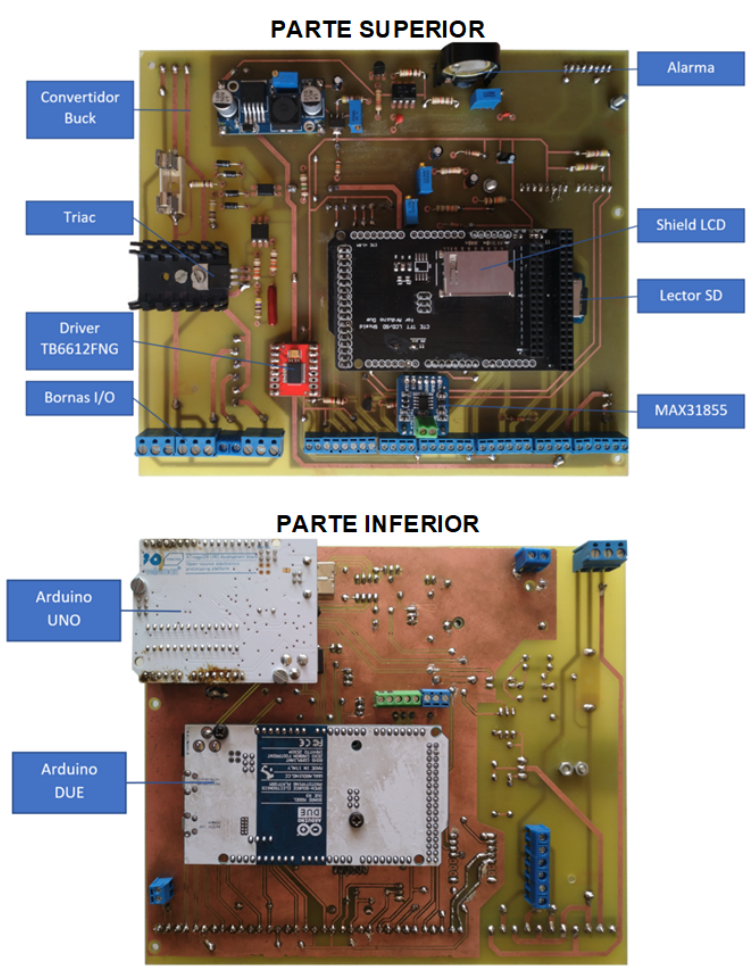

Figura 4: Placa de control

en el depósito para alertar al sistema cuando es necesario reponer el depósito de pellets. Por otra parte, el controlador principal envía órdenes sobre los actuadores de corriente alterna a través del módulo SSR (Solid State Relay): el motor del alimentador del depósito, el motor del alimentador del quemador y la resistencia de encendido.

El Arduino UNO controla la velocidad del ventilador extractor de humos, situado a la salida de gases de la caldera. Este controlador auxiliar se encarga de medir el paso por cero de la corriente alterna y disparar el TRIAC. En la figura Fig. 4 se puede observar el resultado de la placa de control diseñada y construida con todos los elementos del sistema.

Además, el Arduino DUE envía los datos al panel LCD de 5" a través del puerto paralelo para la supervisión del funcionamiento de la caldera. Los datos introducidos por el usuario en el panel táctil (órdenes, consignas y parámetros) se envían por comunicación SPI al controlador principal. En la pantalla se representa la caldera con los valores instantáneos de cada variable. En la parte inferior se encuentran los botones de arranque y parada, y en la parte superior izquierda el botón para acceder a los menús de configuración de parámetros, calibración del ratio de combustible, etc. También se indica la fase en el que se encuentra el sistema.

La placa de control junto con la pantalla táctil, una vez ensambladas, se insertaron en una estructura fabricada por impresión 3D para proporcionar robustez al sistema. El resultado final del panel de control puede verse en la Fig.5.

\subsection{ALGORITMO DE CONTROL IMPLEMENTADO}

El propósito del control del proceso de la combustión es optimizar la eficiencia de la caldera, reducir las emisiones y disminuir en lo posible el ensuciamiento de la caldera. Existen principalmente dos lazos de control en el proceso: el lazo de control de temperatura y el lazo de control de oxígeno.

La temperatura de la caldera es regulada por la 


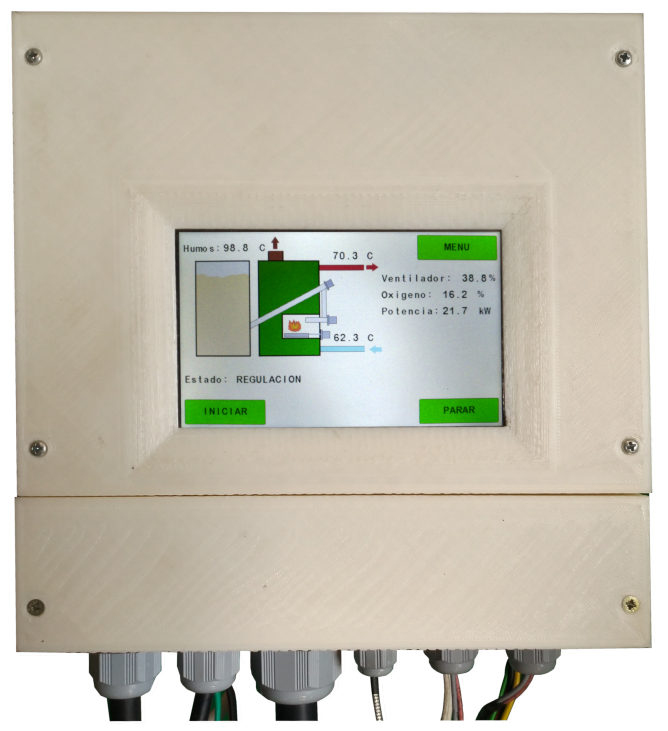

Figura 5: Panel de control dentro de la carcasa

cantidad de combustible en la cámara de combustión. El objetivo es regular la temperatura de ida de la caldera para que cumpla con la normativa RITE (IT 1.3.4.4.1) [3]. La temperatura ideal para una instalación con radiadores será $70^{\circ} \mathrm{C}[9]$.

La regulación del oxígeno se realiza mediante el suministro de aire en el primario y el secundario del quemador a través de la succión o soplado del ventilador. El propósito del primario es el secado, la pirólisis y la combustión final que tiene lugar en la rejilla del quemador. Si no hay aire suficiente en el primario, la quema del carbono se ralentizará causando una disminución de la temperatura y un aumento del tamaño del lecho de combustión. Si hay un exceso de aire en el primario aumentan los NOx, la pirólisis y los gases inquemados [5]. El aire secundario se encarga de proporcionar aire a la combustión de los gases expulsados en la pirólisis. Un elevado suministro de aire secundario disminuye la temperatura de combustión y disminuye el tiempo que reside el gas en la cámara de combustión, lo que se traduce en una disminución de la eficiencia. Además, como consecuencia de ello, se reduce la transferencia de calor ya que los gases salen por la chimenea a mayor temperatura sin aprovechar dicho calor. Una baja alimentación de aire provoca un aumento de eficiencia hasta el punto en el que comienzan a producirse inquemados debido a que no hay suficiente oxígeno para la cantidad de combustible. A partir de ese punto, la eficiencia disminuye [5].

El sistema de control que se ha diseñado pretende reducir las emisiones de los contaminantes atmosféricos CO, OCG y NOx para cumplir con el Reglamento 2015/1189 [7]. El control busca encontrar un equilibrio entre la eficiencia y las emi-

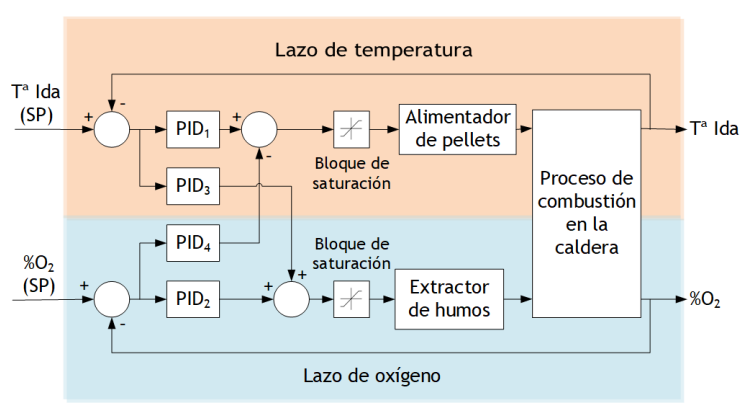

Figura 6: Esquema de control de la combustión

siones de estos contaminantes. Se sabe que con un factor $\lambda>1.3(\lambda=1$ relación estequiométrica combustible-oxígeno) se reducen las emisiones de $\mathrm{CO}$, pero esto supone una reducción en la eficiencia y un aumento de NOx. Con un factor $\lambda<1.3$, se disminuyen las emisiones NOx y aumenta la eficiencia, pero aumentan los valores de emisión de CO [5]. Además, al tener un exceso de aire las emisiones de $\mathrm{CO}_{2}$ aumentan, la temperatura de la llama desciende y como consecuencia se produce una pérdida de eficiencia [5]. Por lo tanto, se puede deducir que la eficiencia de la caldera va estar vinculada con el equilibrio de las emisiones. Además, se deduce que la temperatura de la caldera estará relacionada con el oxígeno presente en la combustión.

El sistema de control de una caldera es un sistema multivariable. En este sistema, una entrada afecta a varias salidas y a su vez una salida es afectada por varias entradas $[4,2]$. La Fig. 6 corresponde con el diseño del sistema de control de la combustión y en él se observan dos lazos de control: el lazo de temperatura y el lazo de oxígeno. El lazo de temperatura basa su funcionamiento en regular la cantidad de combustible introducido a la caldera. El lazo de oxígeno controla la velocidad del extractor de humos para que la combustión sea completa.

Como se comentó previamente, la temperatura y la concentración del oxígeno son variables que se afectan entre sí. Por lo tanto, ambos lazos de control deben interaccionar en el proceso. En el esquema de la Fig. 6 los lazos de oxígeno y temperatura se cruzan para interaccionar el uno con el otro. En este esquema actúan cuatro reguladores PID: dos para los lazos simples de temperatura y oxígeno, y otros dos para los lazos cruzados. De esta manera se puede decidir que lazo tendrá más peso, es decir, se puede decidir si el control del oxígeno es más prioritario que el de la temperatura o viceversa. También se puede decidir si la eficiencia tendrá más importancia que las emisiones o viceversa. Este control es más preciso que un control de lazos simples, ya que disminuye las 


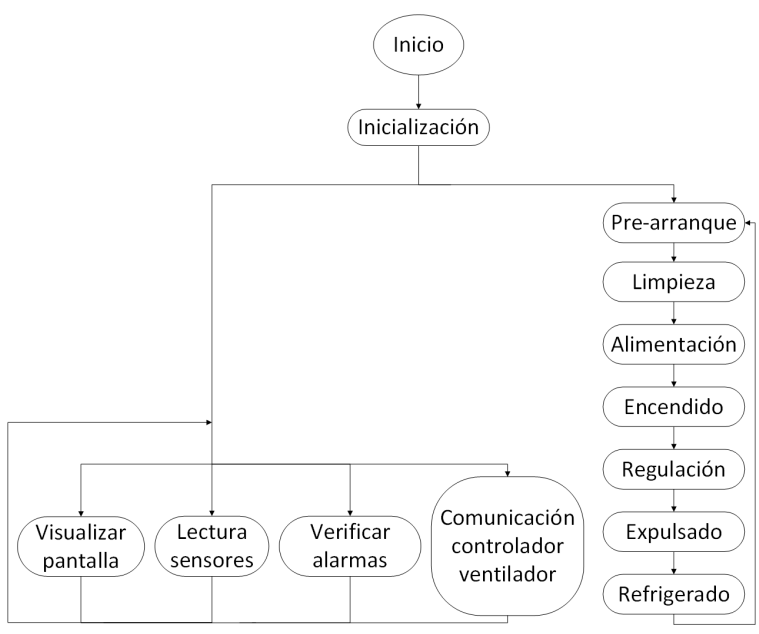

Figura 7: Flujograma del control principal

oscilaciones en la respuesta del motor del ventilador.

El control principal de la caldera se compone de las siguientes fases (véase Fig. 7): inicialización, pre-arranque, limpieza, alimentación, encendido, regulación, expulsado y refrigerado. En la primera fase, que se ejecuta al iniciarse el sistema, se realizan las configuraciones iniciales necesarias para el control de la caldera y el HMI. A continuación, se inicia la fase de pre-arranque, que consiste en verificar una serie de condiciones iniciales cuando el operador a través de la pantalla táctil solicita el arranque de la caldera. Posteriormente, se realizan dos limpiezas para remover la ceniza y limpiar los orificios del quemador. Finalizada la limpieza se introduce en el quemador una dosis de pellets para el encendido. Como el flujo de combustible es mayor en el alimentador del depósito que el del quemador, para que no se produzca un atasco en el quemador, se para el alimentador del depósito a intervalos de tiempo.

En la fase de encendido se activa la resistencia de encendido y se activa el sensor lambda (debe alcanzar la temperatura de trabajo). Al detectar llama se desactiva la resistencia y se pasa a la fase de regulación. Al inicio de esta fase es cuando se activan los 4 reguladores PID para el control automático de la combustión. El sistema tratará de alcanzar y mantener en unos límites la temperatura del agua de la caldera por medio de la regulación de la potencia térmica de la caldera. La potencia de la caldera se determina por el poder calorífico de los pellets y se controla manteniendo constante el tiempo que el alimentador está activado y variando el tiempo que el quemador está desactivado (ratio de combustible). La concentración de oxígeno también se mantendrá en unos límites variando la velocidad del motor del ventilador. Si la entrada del termostato ambiente se desactiva, se desactivará la alimentación hasta que el termostato vuelva a activar la entrada. Si tras la espera se apaga la llama, se iniciará la fase de expulsado. Esta última fase tiene el objetivo de expulsar los pellets del alimentador del quemador para vaciar el sinfín y prevenir un posible retorno del fuego. Tras finalizar el expulsado se realiza una refrigeración de la cámara de combustión y el sistema retorna a la fase de pre-arranque.

\section{RESULTADOS}

El primer ensayo consistió en comprobar la respuesta del nuevo sistema de control y quemador. Primero se realizó una prueba empleando un control de combustión de lazos simples desacoplados, solo con los reguladores $P I D_{1}$ y $P I D_{2}$ activados (véase la Fig. 6). Después se arranca la caldera y cuando se alcanza la fase de regulación, el sistema almacena los datos de $\mathrm{T}^{\mathrm{a}}$, O2, velocidad del ventilador y la carga de combustible (medido en potencia). Los valores de consigna son $70^{\circ} \mathrm{C}$ para la temperatura y $16 \%$ para el oxígeno. La respuesta del sistema de control se puede visualizar en la Fig. 8a.

En el segundo ensayo se llevan a cabo las mismas mediciones que en el primer ensayo y se comprueba la respuesta del sistema mediante un control de combustión de lazos acoplados con los reguladores $P I D_{1}, P I D_{2}, P I D_{3}$ y $P I D_{4}$ activados. Los valores de consigna son $70^{\circ} \mathrm{C}$ para la temperatura y $16 \%$ para el oxígeno. La respuesta del sistema de control se puede visualizar en la Fig. $8 \mathrm{~b}$.

La respuesta del control de lazos acoplados resultó adecuada, ya que se observa una mejoría en la estabilidad de la temperatura del agua y del oxígeno. Por el contrario, el control con lazos simples desacoplados presenta mayor oscilación (ciclo límite) tanto en la temperatura como en el oxígeno. Otra ventaja del control de lazos acoplados es que la acción de control sobre el ventilador extractor de humos y el motor del alimentador de pellets es más progresiva a diferencia del control de lazos simples que es mucho más brusca.

Posteriormente para evaluar la validez del control con respecto a las emisiones, se analizaron los gases de la combustión y el rendimiento de la caldera con un analizador de combustión. Para ello, se realizaron dos ensayos: un ensayo con el nuevo sistema de control y quemador (véase Fig. 9a), y otro con el sistema de control y quemador originales de la caldera: Ecotec 30006 y Ecotec Bioline 25 (veáse Fig. 9b). En cada ensayo se obtuvo el rendimiento de la caldera y los datos fueron un $94,2 \%$ de rendimiento con una temperatura de 


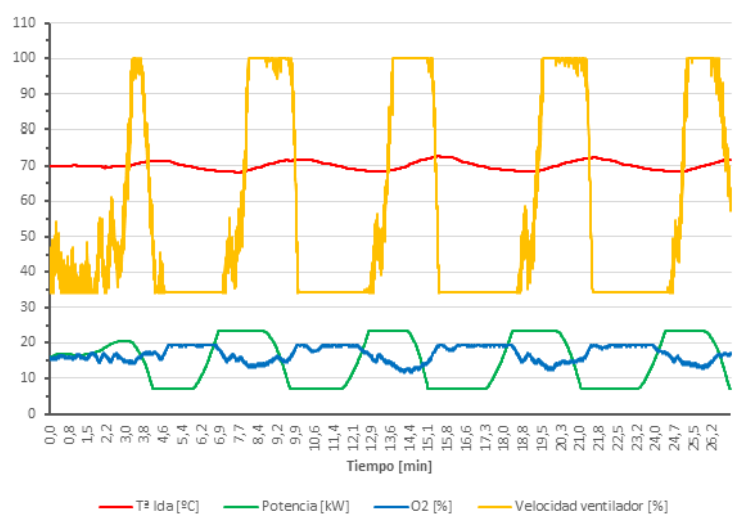

(a) Lazos simples desacoplados

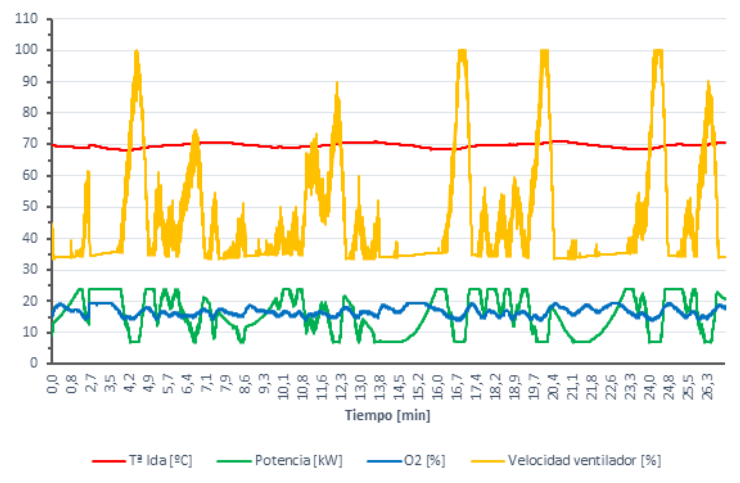

(b) Lazos acoplados

Figura 8: Respuesta del control

humos de $122,6{ }^{\circ} \mathrm{C}$ para el ensayo con el nuevo sistema de control y el nuevo quemador, frente a un $92,4 \%$ de rendimiento con una temperatura de humos de $160,2{ }^{\circ} \mathrm{C}$ para el ensayo con el sistema de control y el quemador originales.

Los resultados del análisis de gases indican que el nuevo sistema de control y el nuevo quemador reducen las emisiones de $\mathrm{CO}$ en un $65,85 \%$, las emisiones de $\mathrm{CO}_{2}$ en un $11,36 \%$ y aumenta el rendimiento un $1.8 \%$.

\section{CONCLUSIONES}

En este trabajo se ha diseñado e implementado un sistema de control para una caldera de biomasa utilizando tecnología abierta y de bajo coste. Previamente, esto ha requerido el diseño y construcción de un nuevo quemador. El nuevo sistema de control y el quemador lograron una considerable reducción en las emisiones de $\mathrm{CO}$ y $\mathrm{CO}_{2}$, además de un control más preciso de la temperatura del agua y del oxígeno en comparación con el quemador original Ecotec Bioline 25 y su sistema de control Ecotec 3006. Se demostró que un control más preciso de la carga de combustible

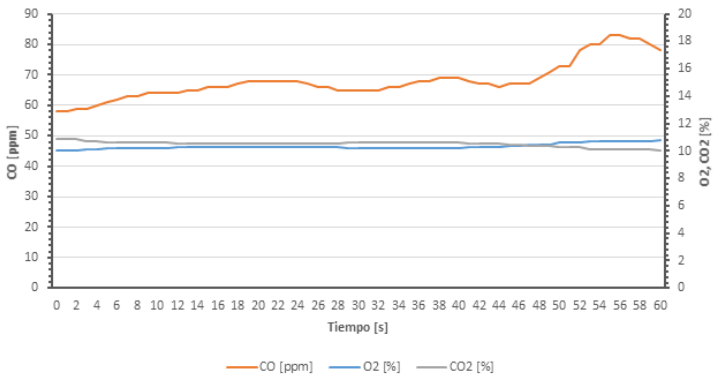

(a) Nuevo sistema de control y quemador

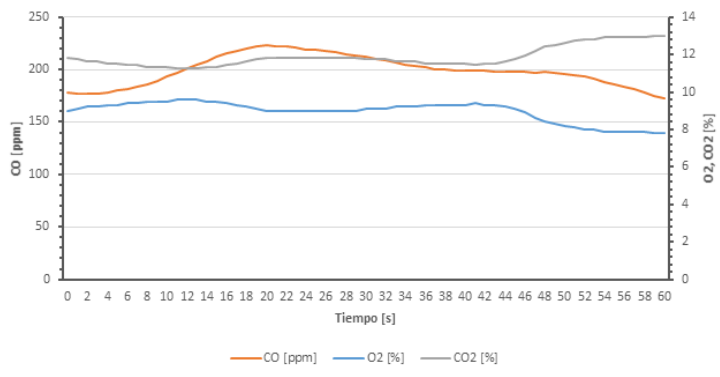

(b) Sistema de control original

Figura 9: Análisis de emisiones

junto con la medición y control de oxígeno en la combustión, puede reducir las emisiones, disminuir el ensuciamiento de la caldera y mantener la caldera en un régimen más estable evitando las paradas debidas al exceso de temperatura. Además, se consiguió disminuir la temperatura de humos de la caldera y como consecuencia, aumentar el rendimiento de la caldera.

El sistema de limpieza requiere ahora de menor mantenimiento, evitando los problemas de obstrucción del alimentador del quemador Ecotec Bioline 20. Los diseños del nuevo quemador y del nuevo control han reducido las posibilidades de retorno de fuego vaciando el alimentador de pellets tras una parada. La instalación de un extractor de humos permitió un mayor suministro de aire necesario para solventar la deficiencia de aire que tenía el quemador Ecotec. La incorporación de la pantalla táctil mejoró la interfaz con el usuario, con un acceso a los menús y la configuración más intuitiva, y una mejora en la visualización de las variables de la caldera.

\section{Agradecimientos}

A José Antonio Balboa Pedreira, por la ayuda en la construcción mecánica del quemador.

Al Proyecto de Investigación DPI2015-69891-C21-R/2-R del Ministerio de Ciencia e Innovación. 


\section{English summary}

\section{CONTROL SYSTEM BASED ON ARDUINO FOR A BIOMASS BOILER}

\begin{abstract}
Biomass is a renewable energy, whose use has been increased in applications such as heating and domestic hot water (DHW). Biomass boilers require ash cleaning and an optimum combustion process for achieving an efficient operation. In this work, the design and implementation of a new burner and its automatic control system for a commercial biomass boiler (25 $\mathrm{kW}$ ) is presented. The main aims of the automatic control system are to reduce emissions, increase efficiency, improve the cleaning system and create a more intuitive monitoring and control panel with for user interface. This control system is based on the open and low cost Arduino platform, so that the user can incorporate future improvements or upgrades in the operating mode. With the developed control system, noteworthy improvements have been achieved in terms of emissions and efficiency.
\end{abstract}

Keywords: Control, Arduino, Boiler, Biomass, Emissions, Efficiency

\section{Referencias}

[1] B. M. Al-Hadithi, C. E. García, R. Cedazo and C. Loor, "Desarrollo de un Sistema de Iluminación Artificial Inteligente para Cultivos Protegidos", Revista Iberoamericana de Automática e Informática Industrial, vol. 13, no. 4, pp. 421-429, 2016.

[2] M. Bhowmick, S. C. Bera, "An approach to optimum combustion control using parallel type and cross-limiting type technique",Journal of Process Control, vol. 22, no. 1, pp. 330-337, 2012.

[3] España. Real Decreto 1027/2007, de 20 de julio, por el que se aprueba el Reglamento de Instalaciones Térmicas en los Edificios. BOE, 29 de agosto de 2007, no. 207, pp. 35931 a 35984 .
[4] I. Fernández, C. Rodríguez, J.L. Guzmán and M. Berenguel, "Control Predictivo por Desacoplo con Compensación de Perturbaciones para el Benchmark de Control 2009-2010", Revista Iberoamericana de Automática e Informática Industrial, vol. 8, no. 2, pp. 112121, 2011.

[5] J. Haapa-Aho, "Combustion Improvement of Small-Scale Pellet Boiler by Continuous Control", 2011. http://dspace.cc.tut.fi/dpub/handle/ $123456789 / 20607$

[6] Hydes, "What is a Draft Inducer and How Does it Improve the Performance of Your Furnace?", Hydes AC \& Heating" 2016. [Online].

[7] IDAE, "Requisitos de ecodiseño para calderas y estufas de biomasa", 2015.

[8] IDAE, "Instalaciones de calefacción individual. Guía técnica", 2012.

[9] IDAE, "Instalaciones de calefacción individual Guía técnica", Madrid, 2012.

[10] IDAE, "El Plan de Energías Renovables 20112020", 2011.

[11] J. Kjällstrand and M. Olsson, "Chimney emissions from small-scale burning of pellets and fuelwood - examples referring to different combustion appliances", Biomass and Bioenergy, vol. 27, no. 6, pp. 557-561, 2004.

[12] R. Saidur, E. A. Abdelaziz, A. Demirbas, M. S. Hossain, and S. Mekhilef, "A review on biomass as a fuel for boilers", Renew. Sustain. Energy Rev., vol. 15, no. 5, pp. 2262-2289, 2011.

[13] S. Van Loo and J. Koppejan, "The handbook of biomass combustion \& co-firing", 1st ed. London: Earthscan, 2008.

[14] World Bioenergy Association, "WBA Global Bioenergy Statistics 2018”, 2018.

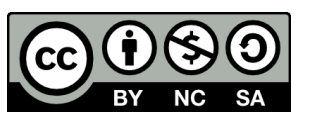
(C) 2019 by the authors. Submitted for possible open access publication under the terms and conditions of the Creative Commons Attribution CC BY-NC-SA 4.0 license (https://creativecommons.org/licenses/by-ncsa/4.0/deed.es). 